\title{
Extreme solar particle events: Can we assess the worst case scenario?
}

\author{
Ilya Usoskin* \\ Space Climate Research Unit and Sodankylä Geophysical Observatory, University of Oulu, \\ FIN-90014 Finland \\ E-mail: ilya.usoskindoulu.fi
}

The era of direct or indirect (ground-based) observations of solar energetic particle (SEP) events covers 50 and 70-80 years, respectively. While thousands of SEP events with soft energy spectra have been recorded directly in space, only about 70 hard-spectrum events detectable at the groundlevel (called GLE - ground-level enhancements) have been identified so far, the greatest one being GLE \#5 on 23-Feb-1956. Yet, for many practical purposes it is important to know whether the Sun can produce even stronger events, how much stronger, and what the expected rate of their occurrence can be. In order to answer these questions, we need to study much longer time scales, covering many millennia, which can be done only using data of cosmogenic radionuclides systematically recorded in natural archives. An overview of the today's knowledge of the extreme SEP events is presented, and assessments of the worst case scenario for the SEP fluence in the vicinity of Earth is made. It is shown that the presently available set of direct data provides insufficient statistic to study extreme events and their occurrence probability distribution. On the other hand, data on cosmogenic radionuclides in terrestrial and lunar samples makes it possible to estimate the probability of extreme events occurrence. It is also shown that the SEP event (or a consequences of events) of $775 \mathrm{AD}$, identified in cosmogenic data as being a factor 40-50 stronger than the greatest GLE \# 5, may serve as a reliable worst-case scenario estimate, but the occurrence rate of such events still remains poorly constratined.

35th International Cosmic Ray Conference - ICRC2017

10-20 July, 2017

Bexco, Busan, Korea

* Speaker. 


\section{Introduction}

While the radiation environment near Earth is mostly defined by galactic cosmic rays, it can be greatly distorted by sporadic solar energetic particle (SEP) events with a greatly enhanced flux of energetic particles [四]. Although their duration is short, hours-days, they pose serious hazards, because of high fluxes, for the modern technological society, and the corresponding risks need to be assessed when designing new satellites or planning space missions. Of particular importance is the question of what is the worst-case scenario (what is the strongest event the Sun can produce?) and how often maysuch events occur? [ [ 2 , [3] Here we try to answer these questions.

\section{Direct SEP measurements}

SEPs are routinely measured by near-Earth satellite, including geostationary GOES-family satellites and L1-tied instruments onboard SOHO mission or Sun-orbiting missions. The strength of SEP events is typically quantified via the event-integrated flux of SEP particles with energy above $30 \mathrm{MeV}$, the so-called $F_{30}$ fluence [四]. This quantity includes the most dangerous, in the sense of space weather hazards, protons with energy of several tens of MeV. It should be noted that early data of the space-borne detectors might have been quite uncertain in evaluating the peak fluxes of SEP because of the possible saturation (leads to an under-estimate of the flux) and contamination through the walls (leads to an over-estimate) effects [ [5, 6$]$. The average $F_{30}$ flux is estimated, for 1954-2006, as about $35 \mathrm{~cm}^{-2} \mathrm{sec}^{-1}$, with the variability between about 10 (for solar cycle 21) and $70 \mathrm{~cm}^{-2} \mathrm{sec}^{-1}$ (for cycle 19) [⿴囗] ]. Usually the average flux is defined by one or few major SEP events rather than a big number of weak events [ [ [ ] ]. The strongest SEP event (with the greatest detected $F_{30}$ fluence) had a very soft energy spectrum took place in August 1972 with the fluence about $7 \times 10^{9} \mathrm{~cm}^{-2}$ [可].

The statistic of the event occurrence (the integral occurrence rate) of the recorded events is shown in Figure $\square$ as open dots (the big black dot corresponds to the event of August 1972 with the greatest recorded $F_{30}$ fluence). One can see that the distribution is very flat, implying that the probability of strong events and moderate events to occur is nearly uniform. There is a tendency to break this relation a bit down for events with $F_{30}>10^{9} \mathrm{~cm}^{-2}$ but statistic is too small. For example, two extrapolations of the occurrence rate [ए]] (applied to the differential distribution of the $F_{10}$ fluence) with the power indices 1.85 and 4 are shown by the dashed and dotted red curves, respectively.

\section{Cosmogenic isotope proxy}

We are not limited by direct observations and can extend our analysis of strong SEP events even further to the past, using the method of cosmogenic isotopes [[13], [4]]. Cosmogenic radionuclides, most useful being ${ }^{14} \mathrm{C}$ and ${ }^{10} \mathrm{Be}$, are produced by cosmic rays in the Earth's atmosphere, stored in natural archives such as tree trunks or ice cores and reveal information on variability of energetic particles in the vicinity of Earth. It was shown [ㄷ]] that such records can potentially provide information about major SEP events in the Past. An example is shown in Figure $\square$ for two overlapping ${ }^{10} \mathrm{Be}$ series, NGRIP and Dye3. Each series exhibits two spikes during the 15th 


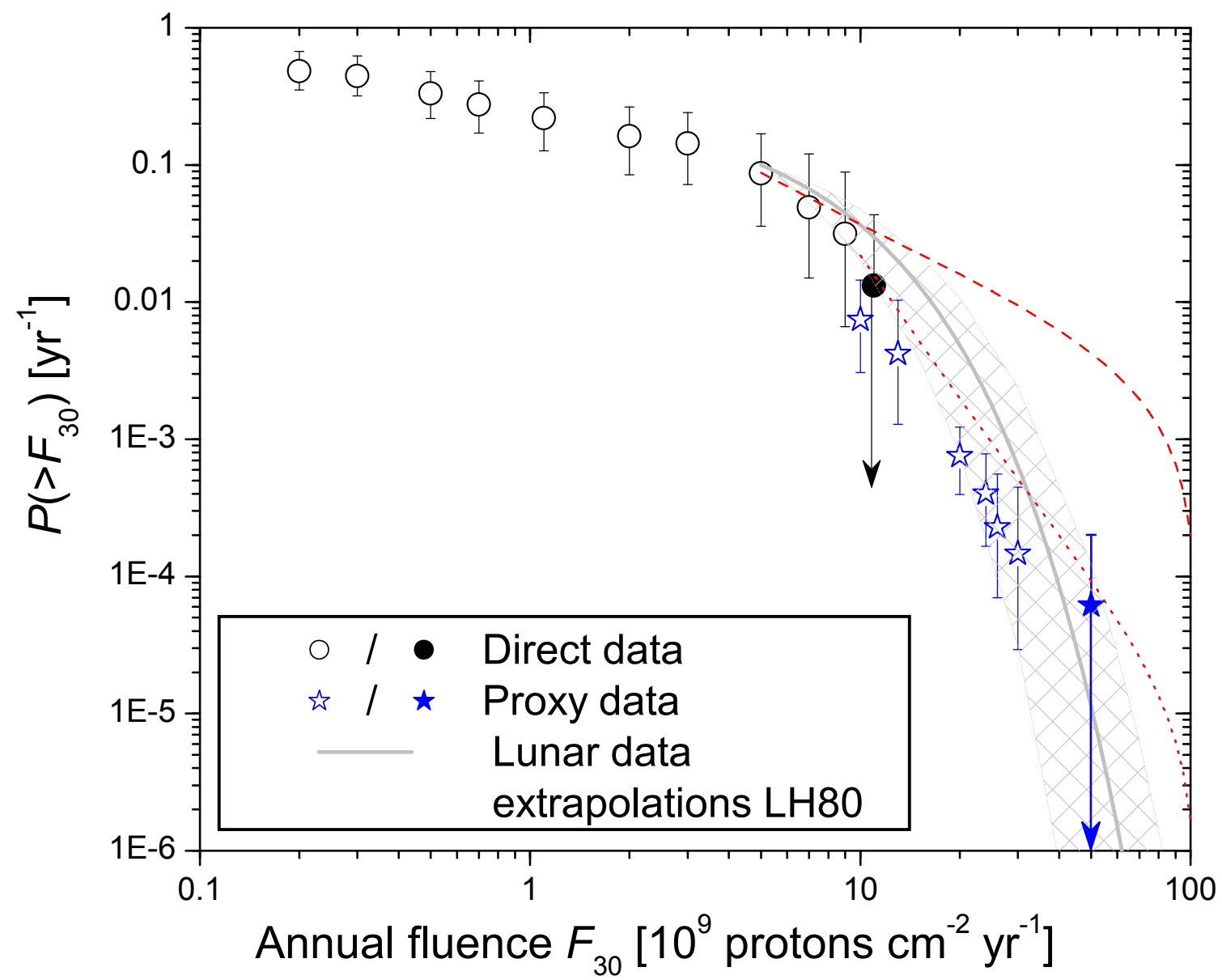

Figure 1: Cumulative occurrence probability density function of SEP events with the $F_{30}$ fluence exceeding the given $F_{30}$ values. The open dots correspond to data available for the era of direct measurements [ $[$, []]. The black dot represents the greatest $F_{30}$ event of August 1972. The red lines bounds the range of extrapolations of the direct data [ए]]. Open stars are estimated using the cosmogenic isotope data ${ }^{14} \mathrm{C}$ and ${ }^{10} \mathrm{Be}$ in terrestrial archives []]. The filled star represents the greatest historical SEP event of 775 AD. The hatched grey area represents an estimate based on lunar samples [ए2].

century, as indicated by the colored stars, but only one of them, ca. $1460 \mathrm{AD}$, is present in both series, considering the possible dating errors of several years [ए]6]. Thus, this spike of ca. $1460 \mathrm{can}$ be considered as a candidate for a strong SEP event. All existed records of cosmogenic isotopes were carefully checked $[\square] \mathrm{m}$, and 23 candidates for the events were selected. While the response of polar ice-core ${ }^{10} \mathrm{Be}$ to an SEP event is expected to be a single 1-2-year spike, the response of ${ }^{14} \mathrm{C}$ is more specific because of the complicated carbon cycle which greatly attenuates and delays the original signal. A typical signal in the measured $\Delta^{14} \mathrm{C}$ has a sharp (1-2 years) peak followed by an exponential decay of the length of several decades (see Figure B]).

A detailed search of the $\Delta^{14} \mathrm{C}$ data was performed by Miyake et al. [10, 201, 2]]. As a result, two events were found, around $775 \mathrm{AD}$ and $994 \mathrm{AD}$. which are now identified as clear SEP events known over millennial time scales [[1, [22, [23, 24]. Both events had very hard energy spectra [22]]. The event of 775 AD remains the strongest known one with the estimated $F_{30}$ fluence being (4- 


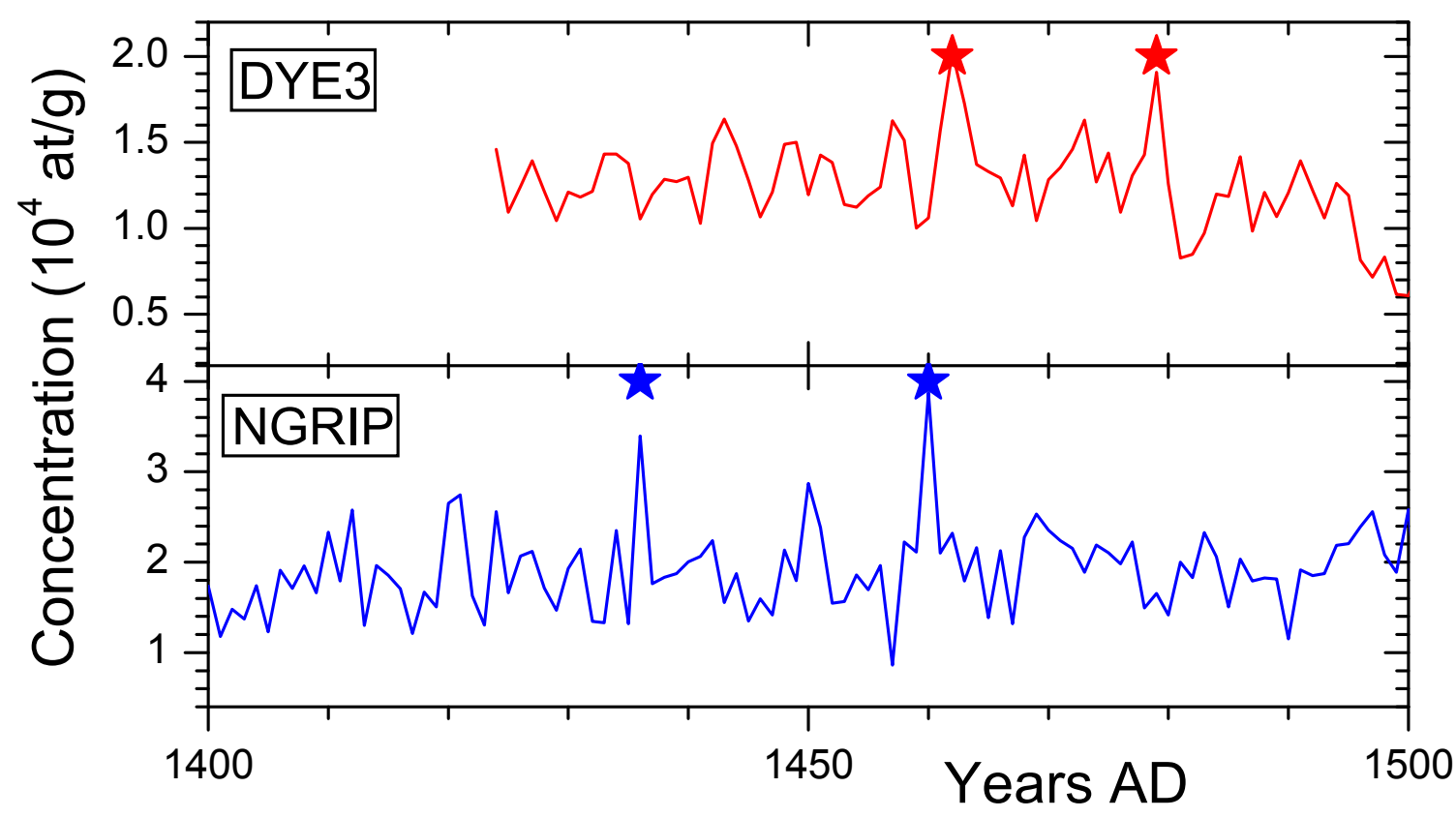

Figure 2: Pseudo-annual records of ${ }^{10} \mathrm{Be}$ from two Greenland ice cores: NGRIP [ए]] and Dye3 [ए8]]. Colored stars depicts spikes in the data.

5) $\times 10^{10} \mathrm{~cm}^{-2}$, viz. a factor of 5-7 greater than that for the greatest directly observed SEP event. On the other hand, in the high-energy part of the spectrum, the event of $775 \mathrm{AD}$ was stronger by a factor of 40-50 than the strongest hard-spectrum observed event of February 1956.

Statistic of the SEP-event candidates identified using data from cosmogenic isotopes is shown in Figure $\square$ as open stars. The solid star corresponds to the event of 775AD. One can see a clear roll-off of the occurrence probability distribution function for $F_{30}>10^{10} \mathrm{~cm}^{-2}$.

Sometimes a record of nitrate in polar ice is used as a proxy for strong SEP events with $F_{30}>10^{9} \mathrm{~cm}^{-2}$ [26, 27]]. However, as shown by several recent studies (e.g., [[28, [29]), nitrate record is not suitable for that. In addition, no nitrate signal was found for the event of $775 \mathrm{AD}$ even though date were of high quality [24].

\section{Lunar samples}

Another method to assess the SEP flux in the Past is related to cosmogenic isotopes measured in lunar rock or fallen meteorites. There is no time resolution there since the archives are not stratified and dateable, but the averaged flux of SEP over the life time of the isotope can be estimated (e.g., [B] ]). This was done elsewhere [ए2], and the result is shown in Figure $\square$ as the hatched area. One can see that the roll-off of the probability function, obtained totally independently from the other methods, is fully consistent with the terrestrial data.

\section{What can be the worst-case scenario?}

So far, only two major SEP events are known over the last 1300 years, in 775 AD and in 994 


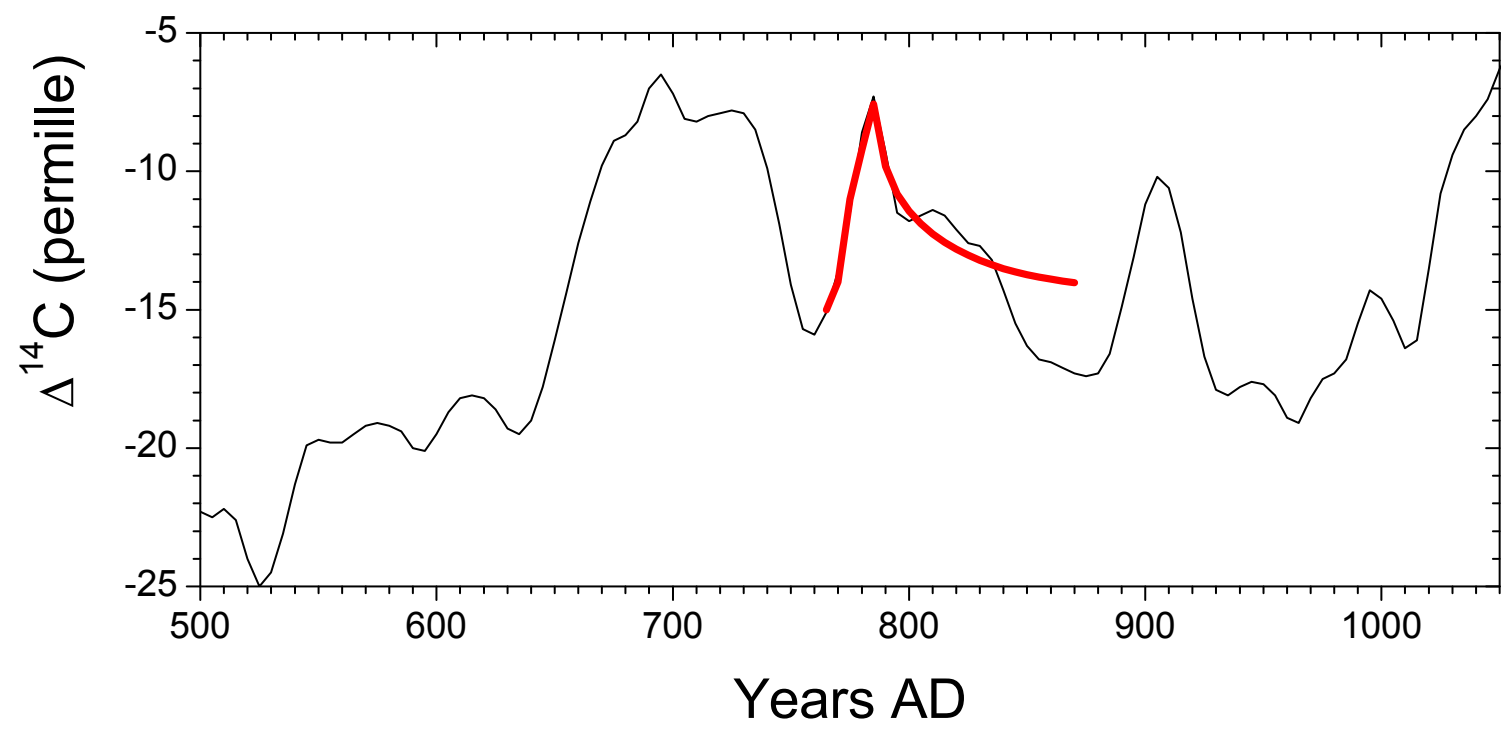

Figure 3: Temporal variability of the measured decadal $\Delta^{14} \mathrm{C}[25]$ around 775 AD. The red curve depicts the modelled profile [22] for the SEP event of 775 AD.

AD. Can we expect the Sun to produce stronger events on longer time scales? While thorough search is still ongoing []] , some basic assessments can be made already now.

The event of $775 \mathrm{AD}$ has the strongest peak $(\approx 0.4 \% / \mathrm{yr})$ in the decadal ${ }^{14} \mathrm{C}$ IntCal dataset, while there are a dozen of smaller but yet comparable peaks $(0.3-0.35 \% / y r)$ in the series. In a recent effort, Miyake et al. [ [R] have measured, with biannual resolution, several such peaks in ${ }^{14} \mathrm{C}$ since $4800 \mathrm{BC}$ and found no other events, implying that the one of $775 \mathrm{AD}$ remains the uniquely high for the last six millennia. There are still large portions of the Holocene unexplored by high-resolution (annual or biannual) measurements, thus leaving room for some events being hidden there. However, can they be stronger than the one of 775 AD? Figure $⿴$ t shows the IntCal $\Delta^{14} \mathrm{C}$ record for the Holocene and several hypothetical spikes (with decadal resolution) caused by a scaled event of $775 \mathrm{AD}$. One can see that an event an order of magnitude greater that that of 775 AD ("10x") is excluded by a simple look at the data. Double strong even ("2x") is hardly possible and may be missing in the decadal data only in an unlikely case of an overlap with a negative dip caused by noise. Events similar to that of $775 \mathrm{AD}$ can be indeed missing in the data and require a high-resolution measurements to be determined, leaving the occurrence rate estimate somewhat uncertain.

\section{Conclusions}

Thus, we conclude that the probability of extreme SEP events to occur drops off quickly for the events with $F_{30}$ fluence exceeding $10^{10} \mathrm{~cm}^{-2}$, as confirmed by different independent datasets. The event of $775 \mathrm{AD}$ [ㅍ, [22, 231, 24] with the estimated fluence $F_{30} \approx 5 \times 10^{10} \mathrm{~cm}^{-2}$ forms the worstcase scenario of a possible SEP events on the time scale of ten millennia, but the exact occurrence rate can not be precisely determined now and requires more detailed measurements of cosmogenic isotopes. 


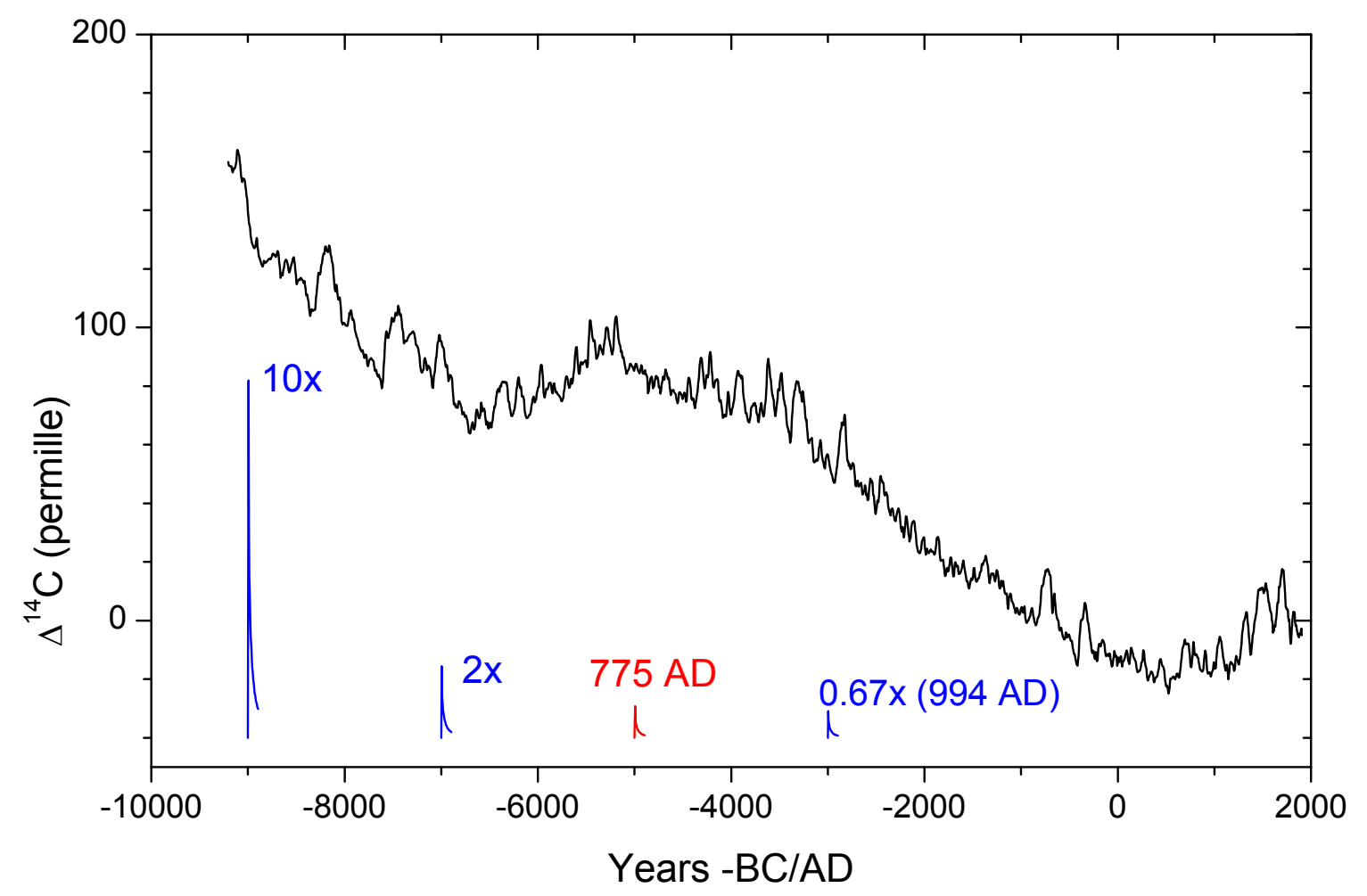

Figure 4: Temporal variability of the measured decadal $\Delta{ }^{14} \mathrm{C}$ for the Holocene [25]. The res spike is the decadal signal for the SEP event of 775 AD (identical to that in Figure 3). Blue spikes are hypothetical events scaled (the scaling factor is denoted next to each curve) from the one of $775 \mathrm{AD}$. The "0.67x" event roughly corresponds to the event of $994 \mathrm{AD}$ [23]. Timing of the colored spikes is arbitrary.

\section{Acknowledgements}

This work was supported by the Center of Excellence ReSoLVE (project No. 272157).

\section{References}

[1] R. Vainio, L. Desorgher, D. Heynderickx, M. Storini, E. Flückiger, R. B. Horne, G. A. Kovaltsov, K. Kudela, M. Laurenza, S. McKenna-Lawlor, H. Rothkaehl, and I. G. Usoskin, Dynamics of the Earth's particle radiation environment, Space Sci. Rev. 147 (2009) 187-231.

[2] H. S. Hudson, Solar flares add up, Nature Phys. 6 (2010), no. 9 637-638.

[3] C. J. Schrijver, J. Beer, U. Baltensperger, E. Cliver, M. Güdel, H. Hudson, K. McCracken, R. Osten, T. Peter, D. Soderblom, I. Usoskin, and E. Wolff, Estimating the frequency of extremely energetic solar events, based on solar, stellar, lunar, and terrestrial records, J. Geophys. Res. 117 (2012) A08103.

[4] D. F. Smart, M. A. Shea, and E. O. Flückiger, Magnetospheric Models and Trajectory Computations, Space Sci. Rev. 93 (2000) 305-333.

[5] G. Reeves, T. Cayton, S. Gary, and R. Belian, The great solar energetic particle events of 1989 observed from geosynchronous orbit, J. Geophys. Res. 97 (1992) 6219-6226. 
[6] A. Tylka, W. Dietrich, and P. Boberg, Probability distribution of high-energy solar-heavy-ion fluxes from imp-8, IEEE Trans. Nucl. Sci. 44 (1997) 2140-2149.

[7] R. Reedy, Recent solar energetic particles: Updates and trends, in Lunar and Planetary Science XXXIII, vol. 33, (Houston, U.S.A.), pp. 1938-1940, Lunar and Planetary Institute, 2002.

[8] M. Shea and D. Smart, Solar proton event patterns: the rising portion of five solar cycles, Adv. Space Res. 29 (2002) 325-330.

[9] A. Tylka and W. Dietrich, A new and comprehensive analysis of proton spectra in ground-level encahnced (gle) solar particle events, in 31th International Cosmic Ray Conference, (Lodź, Poland), Universal Academy Press, 2009.

[10] R. E. Lingenfelter and H. S. Hudson, Solar particle fluxes and the ancient sun, in The Ancient Sun: Fossil Record in the Earth, Moon and Meteorites (R. O. Pepin, J. A. Eddy, \& R. B. Merrill, ed.), (New York and Oxford), pp. 69-79, Pergamon Press, 1980.

[11] I. G. Usoskin and G. A. Kovaltsov, Occurrence of Extreme Solar Particle Events: Assessment from Historical Proxy Data, Astrophys. J. 757 (2012) 92, [arXiv:1207.5932].

[12] G. A. Kovaltsov and I. G. Usoskin, Occurrence Probability of Large Solar Energetic Particle Events: Assessment from Data on Cosmogenic Radionuclides in Lunar Rocks, Solar Phys. 289 (2014) 211-220, [arXiv:1305,5088].

[13] J. Beer, K. McCracken, and R. von Steiger, Cosmogenic Radionuclides: Theory and Applications in the Terrestrial and Space Environments. Springer, Berlin, 2012.

[14] I. G. Usoskin, A History of Solar Activity over Millennia, Living Rev. Solar Phys. 14 (2017) 3.

[15] I. Usoskin, S. Solanki, G. Kovaltsov, J. Beer, and B. Kromer, Solar proton events in cosmogenic isotope data, Geophys. Res. Lett. 33 (2006) L08107.

[16] F. Adolphi and R. Muscheler, Synchronizing the Greenland ice core and radiocarbon timescales over the Holocene - Bayesian wiggle-matching of cosmogenic radionuclide records, Climate of the Past 12 (2016) 15-30.

[17] A.-M. Berggren, J. Beer, G. Possnert, A. Aldahan, P. Kubik, M. Christl, S. J. Johnsen, J. Abreu, and B. M. Vinther, A 600-year annual ${ }^{10}$ Be record from the NGRIP ice core, Greenland, Geophys. Res. Lett. 36 (2009) L11801,.

[18] K. McCracken, F. McDonald, J. Beer, G. Raisbeck, and F. Yiou, A phenomenological study of the long-term cosmic ray modulation, 850-1958 ad, J. Geophys. Res. 109 (2004), no. A18 12103.

[19] F. Miyake, K. Nagaya, K. Masuda, and T. Nakamura, A signature of cosmic-ray increase in ad 774-775 from tree rings in Japan, Nature 486 (2012) 240-242.

[20] F. Miyake, K. Masuda, and T. Nakamura, Another rapid event in the carbon-14 content of tree rings, Nature Comm. 4 (2013) 1748.

[21] F. Miyake, K. Masuda, T. Nakamura, K. Kimura, M. Hakozaki, A. Jull, T. Lange, R. Cruz, I. Panyushkina, C. Baisan, and M. Salzer, Search for Annual 14C Excursions in the Past, Radiocarbon 58 (2016).

[22] I. G. Usoskin, B. Kromer, F. Ludlow, J. Beer, M. Friedrich, G. A. Kovaltsov, S. K. Solanki, and L. Wacker, The AD775 cosmic event revisited: the Sun is to blame, Astron. Astrophys. 552 (2013) L3, [arxiv:1302.6897]. 
[23] F. Mekhaldi, R. Muscheler, F. Adolphi, A. Aldahan, J. Beer, J. McConnell, G. Possnert, M. Sigl, A. Svensson, H. Synal, K. Welten, and T. Woodruff, Multiradionuclide evidence for the solar origin of the cosmic-ray events of AD 774/5 and 993/4, Nature Comm. 6 (2015) 8611.

[24] T. Sukhodolov, I. Usoskin, E. Rozanov, E. Asvestari, W. Ball, M. Curran, H. Fischer, G. Kovaltsov, F. Miyake, T. Peter, C. Plummer, W. Schmutz, M. Severi, and R. Traversi, Atmospheric impacts of the strongest known solar particle storm of 775 AD, Sci. Rep. 7 (2017) 45257.

[25] P. J. Reimer, E. Bard, A. Bayliss, J. W. Beck, P. G. Blackwell, C. B. Ramsey, C. E. Buck, H. Cheng, R. L. Edwards, M. Friedrich, P. M. Grootes, T. P. Guilderson, H. Haflidason, I. Hajdas, C. Hatte, T. J. Heaton, D. L. Hoffmann, A. G. Hogg, K. A. Hughen, K. F. Kaiser, B. Kromer, S. W. Manning, M. Niu, R. W. Reimer, D. A. Richards, E. M. Scott, J. R. Southon, R. A. Staff, C. S. M. Turney, and $\mathrm{J}$. van der Plicht, Intcal13 and marine13 radiocarbon age calibration curves 0-50000 years cal bp, Radiocarbon 55 (2013), no. 4 1869-1887.

[26] G. Dreschhoff and E. Zeller, Evidence of individual solar proton events in antarctic snow, Solar Phys. 127 (1990) 333-346.

[27] K. McCracken, G. Dreschhoff, E. Zeller, D. Smart, and M. Shea, Solar cosmic ray events for the period 1561-1994: 1. identification in polar ice, 1561-1950, J. Geophys. Res. 106 (2001) 21585-21598.

[28] E. W. Wolff, M. Bigler, M. A. J. Curran, J. E. Dibb, M. M. Frey, M. Legrand, and J. R. McConnell, The Carrington event not observed in most ice core nitrate records, Geophys. Res. Lett. 39 (2012) L08503.

[29] K. A. Duderstadt, J. E. Dibb, C. H. Jackman, C. E. Randall, S. C. Solomon, M. J. Mills, N. A. Schwadron, and H. E. Spence, Nitrate deposition to surface snow at Summit, Greenland, following the 9 November 2000 solar proton event, J. Geophys. Res. 119 (2014) 6938-6957.

[30] R. Reedy, Constraints on solar particle events from comparisons of recent events and million-year averages, in Solar Drivers of the Interplanetary and Terrestrial Disturbances (K. Balasubramaniam, S. Keil, and R. Smartt, eds.), vol. 95 of ASP Conference Series, (San Francisco, U.S.A.), pp. 429-436, 1996. 